\section{Reducing Fennel Stand Density Increases Pollen Production, Improving Potential for Pollination and Subsequent Oil Yield}

\author{
Linda M. Falzari, ${ }^{1}$ Robert C. Menary, and Valerie A. Dragar \\ School of Agricultural Science, University of Tasmania, Private Bag 54, Hobart \\ Tasmania 7001 Australia
}

Additional index words. Foeniculum vulgare, Apiaceae, Umbelliferae, protandry, essential oil, plant density, canopy architecture

\begin{abstract}
Fruit set is a key component of essential oil yield from fennel (Foeniculum vulgare Mill.) under Tasmanian conditions. Fruit set in commercial crops is often low, possibly due to incomplete pollination. Fennel flowers are strongly protandrous and a series of flowers must be produced to ensure pollination. The hypothesis tested was that decreasing stand density increases the number of lateral branches, thereby increasing the number of higher order umbels and thus increasing the overlap between the periods of pollen production and stigma receptivity. A field trial was used to examine the number of umbels of each order produced under stand densities of $4,12,25,50$ and 100 plants $/ \mathrm{m}^{2}$. Stand density influenced the ratio of pollen producing to pollen receptive umbels and stand densities of 50 and $100 \mathrm{plants} / \mathrm{m}^{2}$ showed a distinct imbalance between pollen production and stigma receptivity. The data collected supported the hypothesis and it is probable that, in commercial crops, fruit set is being reduced by a lack of synchrony between pollen production and stigma receptivity. The highest stand density tested reduced total oil production. We therefore recommend the inclusion of low stand-density strips within standard-density commercial crops.
\end{abstract}

Fennel (Foeniculum vulgare Mill.), a member of the Apiaceae (Umbelliferae), is a short-lived perennial herb of Mediterranean origin (Pillai and Nambiar, 1982). It is grown commercially in Tasmania, to be steam-distilled for its essential oil. Although oil is produced throughout the plant, $60 \%$ is produced in the fruits and $15 \%$ in the pedicels, i.e., $75 \%$ is produced by the generative or floral canopy (Desmarest, 1978; Peterson, 1990). Trans-anethole, the most valuable component of fennel oil, is produced at highest concentrations in the oil of the fruits (Hunault et al., 1989; Paupardin et al., 1990). Increasing the trans-anethole concentration increases the quality of the oil, consequently, increasing fruit set increases both the yield of oil and also the quality.

Abundant fruit set is frequently observed in wild, weedy stands whereas commercial crops frequently set poorly. Small, research plots often yield proportionally far more than large commercial plantings. A common factor between weed stands and small research plots is the size of the plantings and the fact that the proportion of edge plants to those within the stand is much greater than is found in

Received for publication 5 May 2004. Accepted for publication 4 Oct. 2004. We gratefully acknowledge the Horticultural Research and Development Corporation, Essential Oils of Tasmania Pty Ltd and Natural Plant Extracts Cooperative who provided funding for this research. We thank Peter Cooper, Neville Mendham, and staff of the University Farm for access to and assistance with the field trial. We thank David Ratkowski for assistance with the statistical analyses.

${ }^{1}$ To whom reprint requests should be addressed; e-mail Linda.Falzari@utas.edu.au. large commercial plantings. Edge plants are effectively at a much lower planting density than those within the stand.

Fennel, as a member of the Apiaceae, produces flowers in compound umbels, with each umbel having several whorls of umbellules. Each plant produces one primary umbel, on a central leading stem. Several secondary umbels are produced terminally on lateral branches; tertiary umbels are produced on branches arising from the secondary branches and so on. Plants may produce quaternary and even fifth order umbels (Peterson, 1990).

Plant density influences the canopy architecture of carrot plants (Daucus carota L.), also a member of the Apiaceae. For example, increasing planting density in carrots reduces the number of umbels per plant, reduces the number of lateral branches (Gray et al., 1983) and therefore, the number of secondaries and tertiaries (Noland et al., 1988).

Trials by Desmarest (1978) to determine the optimum stand density for fennel examined densities between 6 and 120 plants $/ \mathrm{m}^{2}$ and found no significant differences between densities of 6,12 , and 24 plants $/ \mathrm{m}^{2}$ for total plant weight, umbel fresh weight or yield of trans-anethole per hectare. In Tasmania, the recommended planting density for commercial crops is 10 to 12 plants $/ \mathrm{m}^{2}$ (Hart, 1987; Peterson, 1990). Previous density trials have concentrated on total yields and have not examined the effect of density on the production of umbels of each order or the relationship between density and pollen production. Density trials on other Umbelliferous crops suggest that the range 4 to 100 plants $/ \mathrm{m}^{2}$ will be necessary to define the upper and lower limits to production
(Gray and Steckel, 1983; Gray and Steckle, 1985; Noland et al., 1988).

Fennel is self-fertile and can be $100 \%$ self-pollinated if out-crossing is prevented but under normal circumstances, it is highly $(80 \%$ to $90 \%$ ) cross-pollinated (Ramanujam et al., 1964 cited in Jansen, 1981; Pillai and Nambiar, 1982). Artificial pollination has been found to improve yield (Choudhry, 1959; Sundararaj et al., 1963).

Fennel is protandrous. That is, within each flower, pollen is shed before the stigma becomes receptive (Sundararaj et al., 1963). Within each umbel and within each umbellule, flowers at the periphery reach anthesis first and those in the centre last. This is directly related to ontogeny (Peterson, 1990). There are differences between varieties but generally the five stamens of each flower emerge sequentially over a 6 to $8 \mathrm{~h}$ period (Sundararaj et al., 1963). These waves of maturity are continued between the umbel orders with the primary umbel maturing first, followed by the secondaries, tertiaries and so on (Bell, 1971).

The contribution of each fennel umbel order to the total oil yield may be expected to change with changing stand density as has been shown for seed yield in carrots (Gray and Steckel, 1983; Noland et al., 1988). The primary umbel is the largest and produces larger seeds, therefore it produces more oil on a per umbel basis (Peterson, 1990). Production by the secondaries will be dependent on plant density. In commercial crops in Tasmania, the planting density is such that the secondaries produce the bulk of the oil yield (Peterson, 1990).

For this study, it was hypothesised that pollination in fennel could be improved by increasing pollen production and stigma receptivity overlap through decreasing plant density.

\section{Materials and Methods}

A trial was conducted at the University Farm, Cambridge, Tasmania, Australia. This area has a cool, temperate climate. The trial was conducted in a single season, on a $50 \times$ $50-\mathrm{m}$ area. The equivalent of $160 \mathrm{~kg} \cdot \mathrm{ha}^{-1}$ of $9 \mathrm{~N}-14 \mathrm{P}-17 \mathrm{~K}$ fertilizer was incorporated into the seedbed prior to the final harrowing.

A commercial mix of two selected fennel populations, C26/C27 (1:2) from Pernod Ricard (France), was sown with a precision drill to give a final plant density of approximately 100 plants $/ \mathrm{m}^{2}$ with an approximately square planting layout. The trial was sown in late spring and measurements made on the plants in their first season of growth.

Trifluralin was used as the preemergent herbicide at a rate of $720 \mathrm{~g} \cdot \mathrm{ha}^{-1}$. The crop was treated with $2.2 \mathrm{~kg} \cdot \mathrm{ha}^{-1}$ of the herbicide Linuron, about $12 \mathrm{~d}$ after sowing. Omethoate was used to control red-legged earth mites (Halotydeus destructor (Tucker)) at the time of germination and Thiometon was applied several times during flowering, to control thrips.

In total, 29 beds were prepared, each $0.3 \mathrm{~m}$ apart and consisting of 12 rows, $0.10 \mathrm{~m}$ apart. A strip $2 \mathrm{~m}$ from the outer boundaries of the trial, was designated as a buffer zone. Treat- 
ment plots were randomly allocated within two blocks, with at least $1 \mathrm{~m}$ internal buffer zone in all directions between plots. Each test plot was one bed $(1.2 \mathrm{~m})$ wide and $0.85 \mathrm{~m}$ long, i.e., about $1 \mathrm{~m}^{2}$ and surrounded by an internal buffer zone to give a total plot of $9 \mathrm{~m}^{2}$ (Fig. 1). At the 6 to 7 fully expanded leaf stage, treatment plots were hand-thinned from the initial stand density of about 100 plants $/ \mathrm{m}^{2}$ to the treatment densities of $4,12,25,50$ and 100 plants $/ \mathrm{m}^{2}$ with an approximately square spacing. The internal buffer zones surrounding each test plot were thinned to the same density as their treatment plot.

Unbalanced replication was used to overcome the higher variability expected from the lower density plots. The 4 and 12 plants $/ \mathrm{m}^{2}$ densities were replicated five times in each of the two blocks. The 25, 50 and 100 plants $/ \mathrm{m}^{2}$ densities were replicated twice in each of the two blocks.

Subsampling was used to reduce sampling time for each of the several measurements, detailed later. At each recording time, all plants from the densities 4,12 , and 25 plants $/ \mathrm{m}^{2}$ were assessed, whereas a subset of 25 plants $/ \mathrm{m}^{2}$ was randomly selected from the densities of 50 and 100 plants $/ \mathrm{m}^{2}$. These plants were marked with tape and the same subset was reassessed at each recording time.

The duration of pollen production and stigma receptivity was recorded throughout the flowering period. At each recording time, each umbel order from the individual plants was examined in turn. Visual observations were used to determine if anthesis had occurred and if pollen grains were present on the anthers. If any of the flowers in that umbel order had pollen present, that order was scored as positive for pollen present; if any of the flowers had receptive stigmas, the umbel order was scored as receptive. Receptive stigmas were defined as those that had elongated above the stylopodium but had not yet turned brown (Hawthorn, 1960). Again, assessment was made visually. This method would overestimate the duration of pollen production since the pollen is viable for only a few hours post anthesis (Baswana, 1984); but since this makes the experimental observations more conservative not less, anthers with any pollen present were deemed to have pollen present.

Natural pollinators were supplemented by the presence of honey-bee hives, situated to the south-east of the trial.

The trial was harvested in late fall (10 to 12 May), at about the time of commercial harvest. Commercial harvest takes place when the umbels have matured to an average moisture content of $55 \%$. The plots were harvested by hand, by cutting entire plants at ground level and the collected material stored at $2{ }^{\circ} \mathrm{C}$ before the measurement of the components of yield. Samples were processed in random order to avoid confounding the treatment effects with possible storage effects. Umbels were counted, weighed and then steam distilled for $2 \mathrm{~h}$ in a cohobation still, using the method documented by Guenther (1972). The oil was collected using a glass condenser and separator. The oil was weighed and dried over anhydrous sodium sulphate.
The trans-anethole content of the oil was determined by gas chromatography, using a Hewlett Packard 5890 series II gas chromatograph fitted with a flame ionisation detector. An SGE BP20 column $(50 \mathrm{~m} \times 0.25 \mathrm{~mm}$ id $)$ was used with nitrogen as the carrier gas, a head pressure of $25 \mathrm{psi}$ and a split ratio of $50: 1$. The detector temperature was $250^{\circ} \mathrm{C}$ and the injector temperature $240^{\circ} \mathrm{C}$. The oven temperature program began at $50{ }^{\circ} \mathrm{C}$ for 1 minute, then increased from 50 to $200{ }^{\circ} \mathrm{C}$ at a rate of $9{ }^{\circ} \mathrm{C}$ perminute, and was held at the final temperature of $200^{\circ} \mathrm{C}$ for 12.3 minutes. Each injection was of $1 \mu \mathrm{L}$ from a sample solution of $5 \mu \mathrm{L}$ of oil in $1 \mathrm{~mL}$ of HPLC grade $\mathrm{n}$-hexane.

The umbel number, pollen production and stigma receptivity data were adjusted for subsampling and used to estimate the mean number of umbels $/ \mathrm{m}^{2}$ with flowers at anthesis and flowers with receptive stigmas, for each recording date.

Fruit was deemed to have set when they had begun to swell and to darken in color.
Percentage fruit set was determined by dividing the number of fruits by the number of pedicels (potential fruit). Percentage fruit set was divided into inner and outer whorls.

SAS (1996) procedures proc glm and proc corr, using the Type III sums of squares method for calculating the error variance of unbalanced data, were used to analyse the data for statistical differences. Least squares means were also calculated (SAS, 1996).

\section{Results}

The results of the experimental program highlight the relationship between stand density, canopy architecture and crop yield.

Number of umbels. The total number of umbels (all orders combined) per unit area, was not significantly $(p>0.05)$ altered by stand density (Table 1). Plots with high stand densities had fewer umbels per plant in comparison to plots with low stand densities; e.g., at a stand density of 100 plants $/ \mathrm{m}^{2}$ each

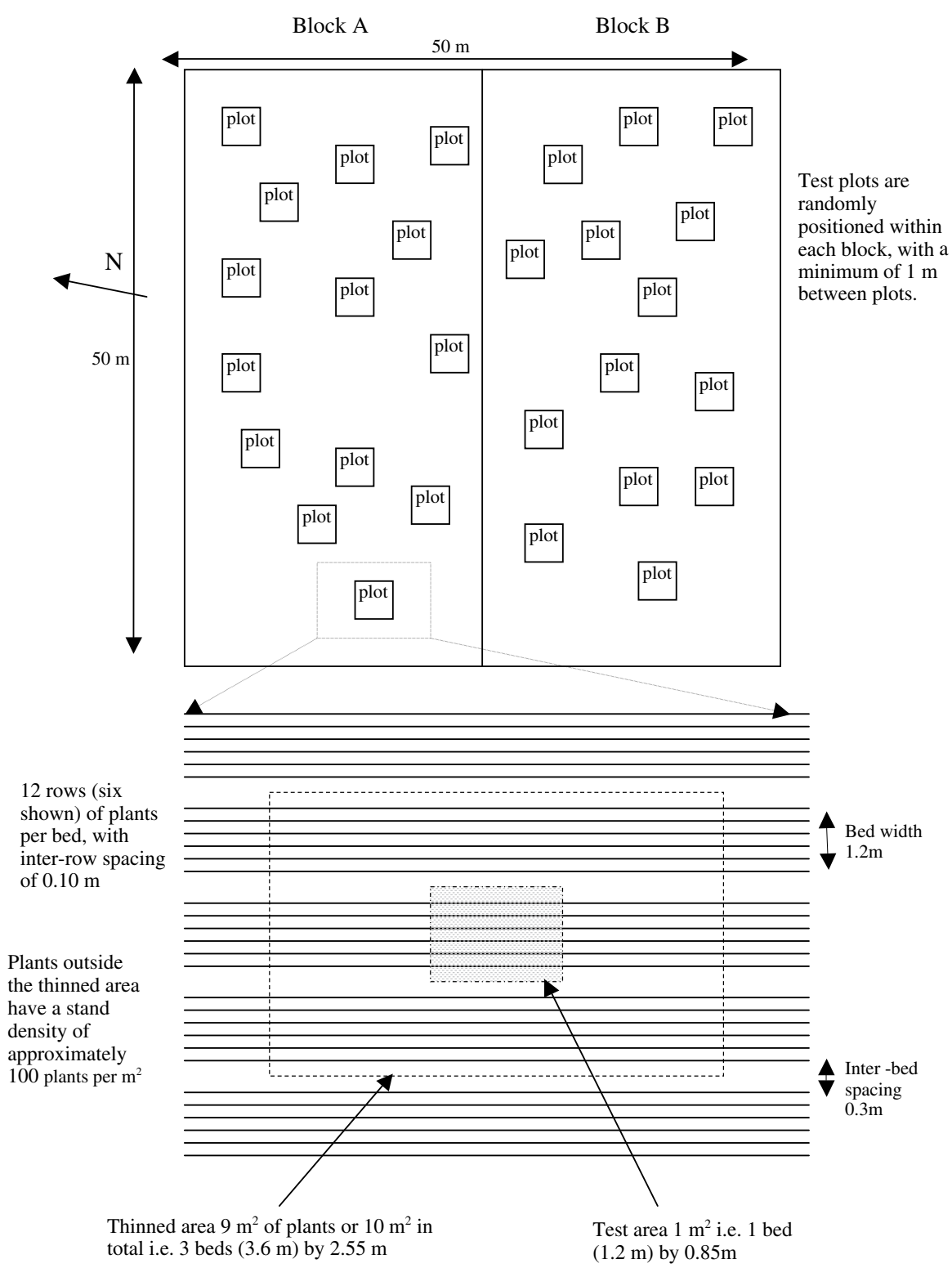

Fig. 1. Experimental layout illustrating the relationship between the test areas and buffers relative to the total trial. 
Table 1. The effect of density on the number of umbels per square meter and per plant (standard errors in parentheses).

\begin{tabular}{lcccccc}
\hline Density (plants $\left./ \mathrm{m}^{2}\right)$ & 4 & 12 & 25 & 50 & 100 & Significance \\
\hline $1^{\circ} \mathrm{umbels} / \mathrm{m}^{2}$ & $3.9(0.1)$ & $12(0)$ & $24(0.5)$ & $46(2.1)$ & $77(4.2)$ & $* * *$ \\
$2^{\circ}$ umbels $/ \mathrm{m}^{2}$ & $43(1.2)$ & $103(4.6)$ & $159(6.1)$ & $201(17)$ & $292(19)$ & $* * *$ \\
$3^{\circ}$ umbels $/ \mathrm{m}^{2}$ & $385 \mathrm{a}(36)$ & $444 \mathrm{a}^{\mathrm{z}}(71)$ & $300 \mathrm{ab}(37)$ & $212 \mathrm{~b}(59)$ & $182 \mathrm{~b}(38)$ & $* * *$ \\
$1^{\circ}$ umbels/plant & 0.98 & 1 & 0.96 & 0.92 & 0.77 & \\
$2^{\circ} \mathrm{umbels} / \mathrm{plant}$ & 11 & 9 & 6 & 4 & 3 & \\
$3^{\circ} \mathrm{umbels} / \mathrm{plant}$ & 96 & 37 & 12 & 4 & 2 & \\
Total umbels $/ \mathrm{m}^{2}$ & $432 \mathrm{a}(37)$ & $559 \mathrm{a}(73)$ & $483 \mathrm{a}(43)$ & $459 \mathrm{a}(77)$ & $551 \mathrm{a}(56)$ & NS \\
Total umbels/plant & 108 & 47 & 19 & 9 & 6 & \\
\hline
\end{tabular}

${ }^{2}$ For each umbel order, means annotated with the same subscript are not significantly different at the $5 \%$ probability level

NS,*,**,**** Density effect on means is nonsignificant or significant at the $5 \%, 1 \%$, or $0.1 \%$ probability level, respectively.

plant had an average of 6 umbels whereas at a stand density of 4 plants $/ \mathrm{m}^{2}$ each plant had an average of 108 umbels.

Stand density altered the apportionment of total umbel number (per plant and per unit area) into numbers of umbels of each order, resulting in substantially different canopy architectures (Table 1 and Fig. 2). Per unit area, the number of both primary and secondary umbels increased from 3.9 and $43 \mathrm{umbels} / \mathrm{m}^{2}$ respectively for 4 plants $/ \mathrm{m}^{2}$ to 77 and 292 umbels $/ \mathrm{m}^{2}$ respectively for 100 plants $/ \mathrm{m}^{2}$. The number of tertiary umbels decreased with increasing stand density from 385 umbels $/ \mathrm{m}^{2}$ for a stand density of 4 plants $/ \mathrm{m}^{2}$ to $182 \mathrm{um}$ bels $/ \mathrm{m}^{2}$ for 100 plants $/ \mathrm{m}^{2}$. On a per plant basis, there was approximately one primary umbel per plant for stand densities between 4 and 50 plants $/ \mathrm{m}^{2}$. At a stand density of 100 plants $/ \mathrm{m}^{2}$, there were 0.77 primary umbels per plant. The number of secondary and tertiary umbels decreased with increasing plant density from 11 and 96 umbels per plant for secondary and tertiaries respectively at 4 plants $/ \mathrm{m}^{2}$ to 3 and 2 umbels per plant for secondaries and tertiaries respectively at 100 plants $/ \mathrm{m}^{2}$.

The canopy depth, being the difference in height above the ground of the highest and lowest umbels, is decreased with increasing plant density (Fig. 2).

Tertiary umbel size, measured by the number of rays per umbel, decreased significantly $(p<0.01)$ with increasing stand density (Table 2). Primary and secondary umbel size was not shown by ANOVA to be significantly affected $(p>0.05)$ by stand density, but an apparent trend for decreasing umbel size was observed. This trend was examined by correlation analysis (proc corr, SAS 1996). It was found that a correlation exists between stand density and primary umbel size (correlation coefficient, $r$ $=-0.39, p<0.05$ ) but there was no significant correlation between secondary umbel size and stand density $(p>0.05)$.

Pollen production and stigma receptivity. The relationship between pollen production and stigma receptivity changes over the season (Fig. 3A-C). At each recording time, the relative height of each pair of columns on the histograms illustrates the total number of umbels producing pollen compared with the number of umbels having receptive stigmas. There is some overlap between these categories with some umbels producing pollen on the inner umbellules while the outer umbellules are receptive and the total height of the two columns can represent more than the total

Early in the season, the number of pollen producing umbels exceeds the number with eptive stigmas. Pollen production and indications are that there is sufficien pollen for adequate pollination of the receptive umbels. Later in the season, the number of receptive umbels increases relative to the number of pollen producing umbels and the balance between pollen production and stigma vegetative and generative canopies. number of umbels producing pollen exceeds the number of umbels having receptive stigmas until 5 Mar. for stand densities of 4 and 12 plants $/ \mathrm{m}^{2}$. At 25 plants $/ \mathrm{m}^{2}$, pollen producing umbels exceed those with receptive stigmas only until $17 \mathrm{Feb}$. and for 50 and 100 plants $/ \mathrm{m}^{2}$ the change in balance occurs even earlier, on $10 \mathrm{Feb}$. In addition, the degree of imbalance is exaggerated at higher planting densities. The three illustrated treatments (Fig. 3A-C) show a trend for increasing stand density to greatly decrease pollen production late in the season, when the demand for pollen is high, due to a high number of receptive umbels. The two density treatments not shown also follow this same trend.

The length of the flowering period varied with planting density. The first primary umbels reached anthesis in mid-January, at all planting densities. Anthesis of the primary umbels extended over an increasingly long period with increasing planting density; being completed in about $3 \mathrm{~d}$ at 4 and 12 plants $/ \mathrm{m}^{2}$ but continuing for $8 \mathrm{~d}$ at 25,50 , and 100 plants $/ \mathrm{m}^{2}$. The same is true for stigma receptivity. Primary umbel flowering was complete and fruit had either set or aborted, (defined as stigma turned brown), by the end of January in the lower stand densities. Pollen was still being produced by the primary ity is lost. The timing of this cha in relationship depends on stand density. The
$1.6 \mathrm{~m}$
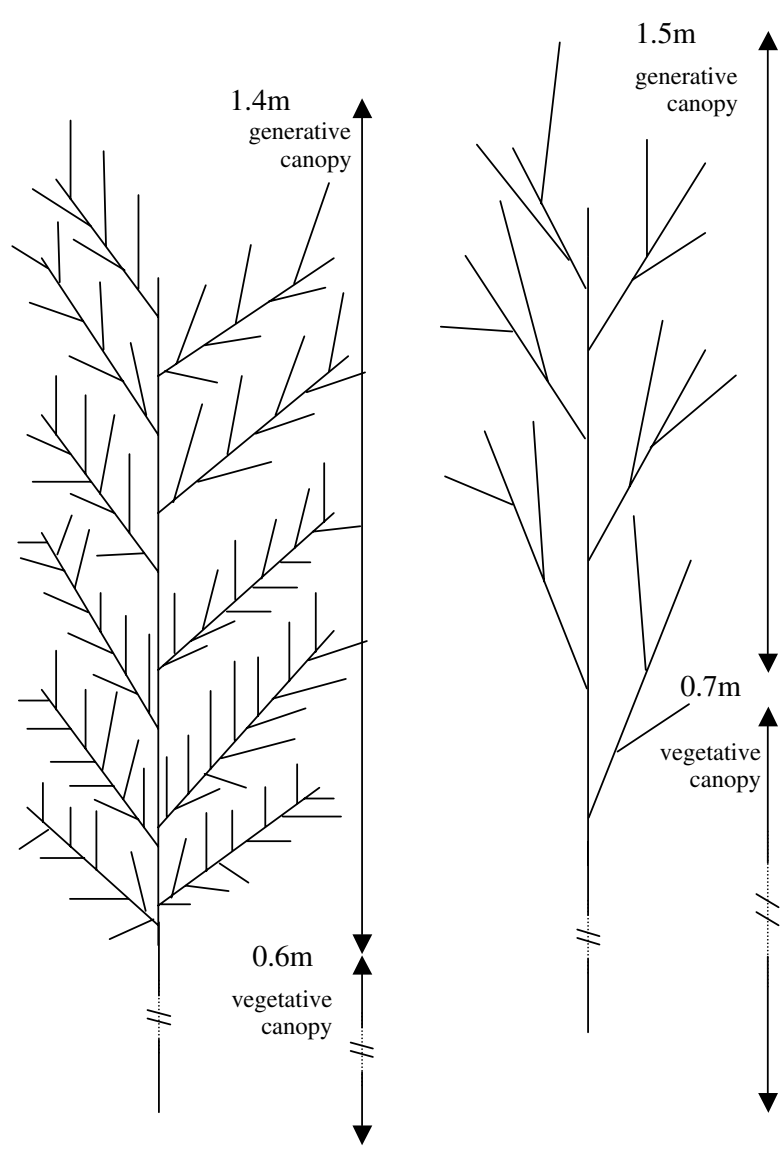

4 plants $/ \mathrm{m}^{2} \quad 25$ plants $/ \mathrm{m}^{2} \quad 100 \mathrm{plants} / \mathrm{m}^{2}$

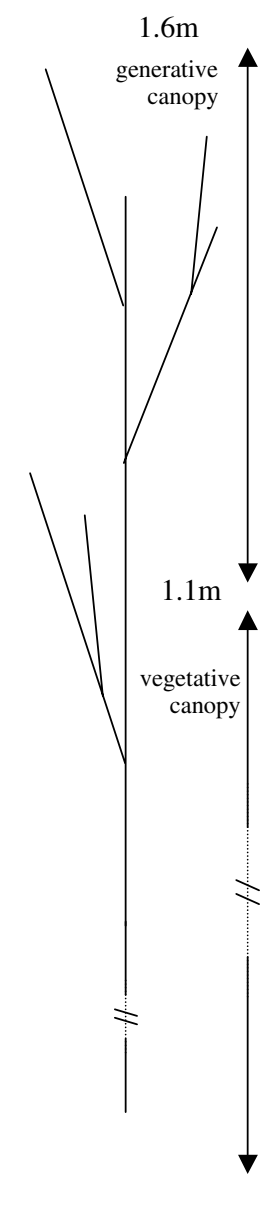

Fig. 2. Schematic diagram showing typical plant for each of 4, 25, and $100 \mathrm{plants} / \mathrm{m}^{2}$. Each line on the diagram represents a branch terminated by an umbel. Heights refer to the height above ground of the 
Table 2. The effect of density on umbel size, as measured by the number of rays (umbellules) per umbel (standard errors in parentheses).

\begin{tabular}{|c|c|c|c|c|c|c|}
\hline Density (plants $/ \mathrm{m}^{2}$ ) & 4 & 12 & 25 & 50 & 100 & Significance \\
\hline Rays $/ 1^{\circ}$ umbel & $16.8 \mathrm{a}(0.49)$ & $17.0 \mathrm{a}(0.80)$ & $15.9 \mathrm{a}(0.76)$ & $15.5 \mathrm{a}(0.96)$ & $15.0 \mathrm{a}(0.82)$ & NS \\
\hline Rays $/ 3^{\circ}$ umbel & 15.9 a (0.78) & $14.1 \mathrm{ab}(0.99)$ & $13.0 \mathrm{bc}(0.60)$ & $12.1 \mathrm{bc}(1.20)$ & $8.5(0.87)$ & $* * *$ \\
\hline
\end{tabular}

${ }^{2}$ For each umbel order, means annotated with the same subscript are not significantly different at the $5 \%$ probability level

$\mathrm{NS}_{,}^{*, * * * * * * *}$ Density effect on means is nonsignificant or significant at the $5 \%, 1 \%$, or $0.1 \%$ probability level, respectively.

umbels in the higher stand densities, until the first week of February.

In contrast, the overall flowering period (anthesis of primaries to end of stigma receptivity of tertiaries) was shorter at the higher stand densities than at the lower. At a planting density of 100 plants $/ \mathrm{m}^{2}$ flowering was effectively completed early in March but when the planting density was 4 plants $/ \mathrm{m}^{2}$, active flowers were still present in mid-March.

Fruit set. Across all stand densities, umbellules on outer whorls set significantly more fruit $(p<0.01)$ than the inner umbellules, with outer umbellules setting $71 \%$ and inner umbellules setting $55 \%$ of their potential fruit. There was no statistically significant interaction between density and umbellule position or between umbel order and umbellule position.

Density significantly affected fruit set $(p<0.05)$ as did umbel order $(p<0.05)$ and there was a significant density by umbel order interaction $(p<0.05)$. Means for these variables are presented in Table 3.

The general trend is for primary umbels to set a higher percentage of fruit than secondaries, which in turn set a higher percentage than the tertiaries. The trend is statistically significant $(p<0.05)$ for all means except that difference between percentage seed set for the primaries and secondaries is not significantly different for stand densities of 4 and 25 plants $/ \mathrm{m}^{2}$.

In the comparison of primary umbels from different stand densities; there are no

Fig. 3. The relationship between pollen production and stigma receptivity. The number of umbels of each order having flowers either at anthesis (pollen) or with receptive stigmas (receptive) at each sampling date, for planting densities of (A) 4, (B) 25, and (C) 100 plants $/ \mathrm{m}^{2}$. Standard error bars show the error associated with the total number of umbels not the error associated with each umbel order. significant differences in percentage seed set between any treatments. For the secondary umbels, percentage seed set was higher for a stand density of 4 plants $/ \mathrm{m}^{2}$ than for any other stand density. There were no other significant effects. Within the tertiary umbel order, stand densities of 4,12 , and 25 plants $/ \mathrm{m}^{2}$ did not set significantly different percentages of seed. However, all three of these lower stand densities set significantly more seed $(p<0.05)$ than the stand densities of 50 and 100 plants $/ \mathrm{m}^{2}$.

Yield. The oil yield from the primary and tertiary umbels was significantly influenced by density whereas total oil yield was only marginally affected $(p<0.1)$. Density did not significantly affect the oil yield from secondary umbels (Table 4). The oil yield $/ \mathrm{m}^{2}$ of the primaries increased with density from
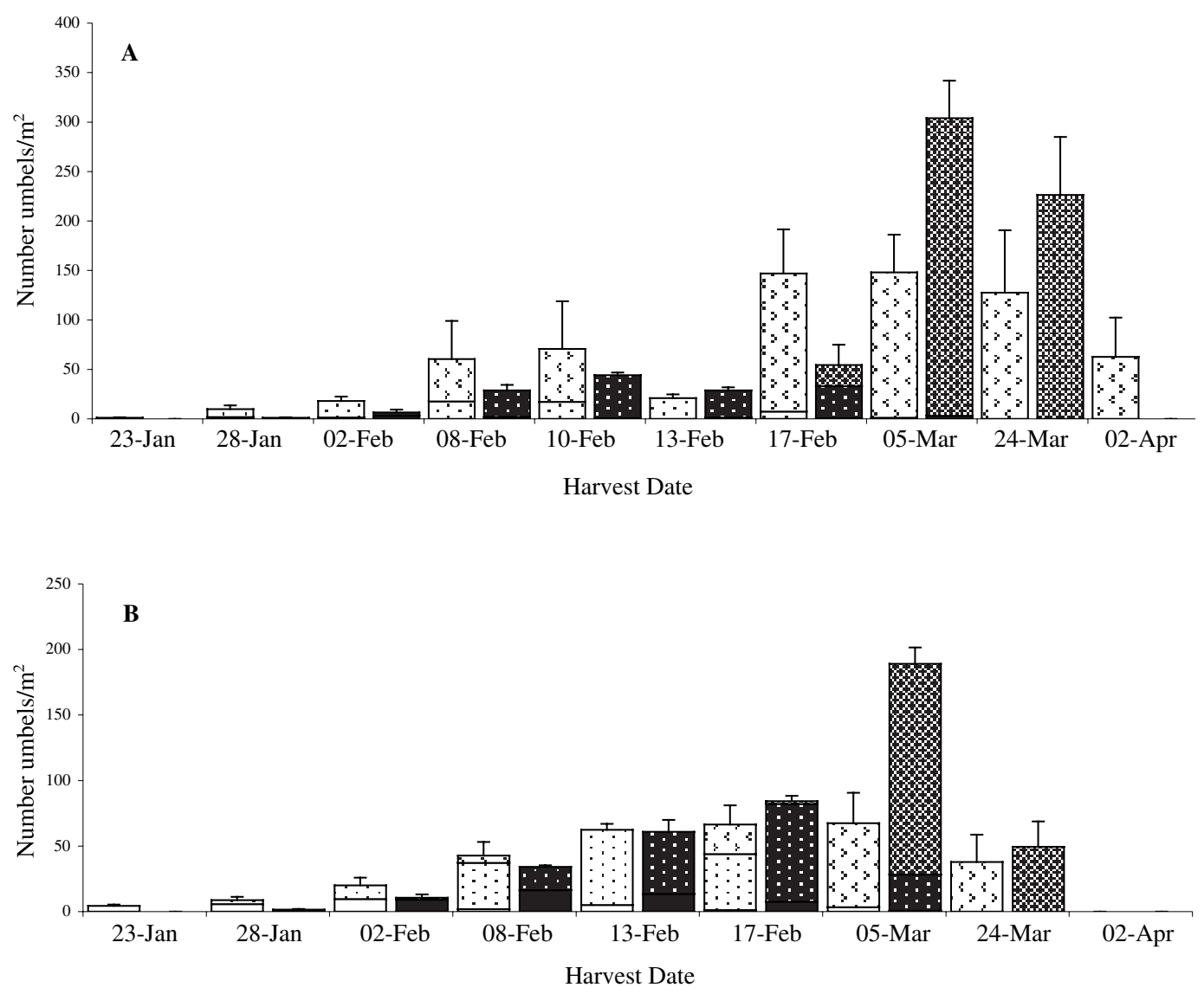

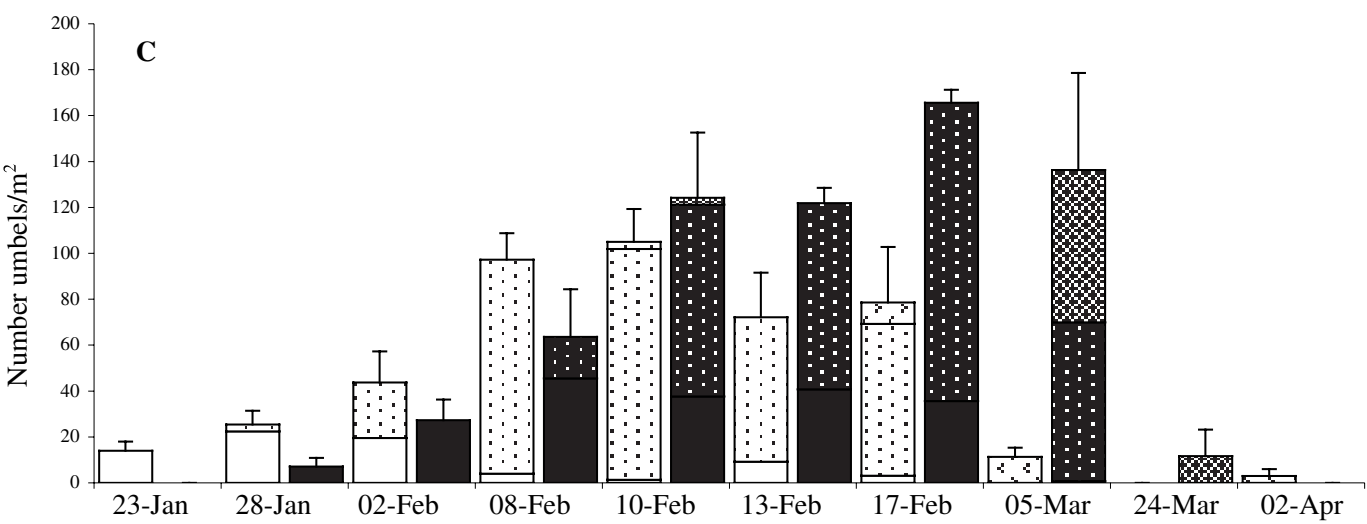

Harvest Date

$\square 1^{\circ}$ pollen $\quad \therefore 2^{\circ}$ pollen $\quad \because 3^{\circ}$ pollen $\quad 1^{\circ}$ receptive $\quad \because 2^{\circ}$ receptive $\quad 3^{\circ}$ receptive


Table 3. The effect of density on percentage fruit set (standard errors in parentheses).

\begin{tabular}{lcccccc}
\hline Density (plants $\left./ \mathrm{m}^{2}\right)$ & 4 & 12 & 25 & 50 & 100 & Significance \\
\hline Percent fruit set $1^{\circ}$ umbel & $83 \mathrm{a} \mathrm{(2.2)}$ & $74 \mathrm{a}(3.8)$ & $72 \mathrm{a}(5.3)$ & $80 \mathrm{a}(3.5)$ & $77 \mathrm{a}(2.8)$ & NS \\
Percent fruit set $2^{\circ}$ umbel & $81 \mathrm{a} \mathrm{(2.4)}$ & $58 \mathrm{a}(4.6)$ & $61 \mathrm{a}(7.0)$ & $56 \mathrm{a}(7.8)$ & $48 \mathrm{a}(2.8)$ & $*$ \\
Percent fruit set $3^{\circ}$ umbel & $51 \mathrm{a} \mathrm{(3.8)}$ & $48 \mathrm{a} \mathrm{(3.8)}$ & $50 \mathrm{a}(8.8)$ & $31 \mathrm{~b}(5.7)$ & $36 \mathrm{~b}(7.4)$ & $*$
\end{tabular}

${ }^{\mathrm{z} F o r}$ each umbel order, means annotated with the same subscript are not significantly different at the $5 \%$ probability level.

$\mathrm{NS}, *, * * * * * *$ Density effect on means is nonsignificant or significant at the $5 \%, 1 \%$, or $0.1 \%$ probability level, respectively.

Table 4. The effect of density on yield.

\begin{tabular}{|c|c|c|c|c|c|c|}
\hline $\begin{array}{l}\text { Density } \\
\left.\text { (plants } / \mathrm{m}^{2}\right)\end{array}$ & 4 & 12 & 25 & 50 & 100 & Significance \\
\hline \multicolumn{7}{|c|}{ Oil yield $\left(\mathrm{g} \cdot \mathrm{m}^{-2}\right)$} \\
\hline $1^{\circ}$ & $\begin{array}{c}0.84 \\
(0.052)\end{array}$ & $\begin{array}{l}2.02 \mathrm{a}^{\mathrm{z}} \\
(0.155)\end{array}$ & $\begin{array}{c}2.52 \mathrm{a} \\
(0.201)\end{array}$ & $\begin{array}{c}4.27 \\
(0.517)\end{array}$ & $\begin{array}{c}3.50 \\
(0.147)\end{array}$ & $* * *$ \\
\hline $2^{\circ}$ & $\begin{array}{c}5.95 \mathrm{a} \\
(0.306)\end{array}$ & $\begin{array}{l}7.88 \mathrm{a} \\
(1.00)\end{array}$ & $\begin{array}{c}7.03 \mathrm{a} \\
(0.901)\end{array}$ & $\begin{array}{c}6.85 \mathrm{a} \\
(1.498)\end{array}$ & $\begin{array}{c}4.73 \mathrm{a} \\
(0.840)\end{array}$ & NS \\
\hline $3^{\circ}$ & $\begin{array}{c}6.66 \mathrm{a} \\
(0.455)\end{array}$ & $\begin{array}{c}5.62 \mathrm{a} \\
(0.836)\end{array}$ & $\begin{array}{l}2.98 \mathrm{~b} \\
(0.457)\end{array}$ & $\begin{array}{l}1.82 \mathrm{bc} \\
(0.726)\end{array}$ & $\begin{array}{c}0.81 \mathrm{c} \\
(0.053)\end{array}$ & $* * *$ \\
\hline Total & $\begin{array}{c}13.4 \mathrm{a} \\
(0.635)\end{array}$ & $\begin{array}{c}5.5 \mathrm{a} \\
(1.751)\end{array}$ & $\begin{array}{c}12.5 \mathrm{a} \\
(1.352)\end{array}$ & $\begin{array}{c}12.9 \mathrm{a} \\
(2.647)\end{array}$ & $\begin{array}{c}9.04 \\
(0.875)\end{array}$ & NS \\
\hline \multicolumn{7}{|c|}{ Oil yield (g/plant) } \\
\hline $1^{\circ}$ & 0.21 & 0.16 & 0.10 & 0.085 & 0.035 & \\
\hline $2^{\circ}$ & 1.49 & 0.66 & 0.28 & 0.14 & 0.047 & \\
\hline $3^{\circ}$ & 1.67 & 0.47 & 0.12 & 0.036 & 0.0081 & \\
\hline Total & 3.35 & 1.29 & 0.50 & 0.26 & 0.09 & \\
\hline \multicolumn{7}{|c|}{ Trans-anethole in oil $(\%, \mathrm{w} / \mathrm{w})$} \\
\hline $1^{\circ}$ & 75 a $(0.6)$ & 73 b (0.8) & $74 \mathrm{ab}(1.0)$ & $71 \mathrm{~b}(0.6)$ & 73 b (0.3) & $* *$ \\
\hline $2^{\circ}$ & 72 a $(0.4)$ & 70 bc $(0.6)$ & 70 bc $(0.8)$ & 70 bc (0.3) & 72 ac (0.5) & $*$ \\
\hline $3^{\circ}$ & 70 a $(0.5)$ & 70a (1.0) & $71 \mathrm{ab}(0.9)$ & 73 bc (0) & 75 c (0.9) & $* * *$ \\
\hline
\end{tabular}

${ }^{\mathrm{z}}$ For each umbel order, means annotated with the same subscript are not significantly different at the $5 \%$ probability level.

NS,*,**,*** Density effect on means is nonsignificant or significant at the $5 \%, 1 \%$, or $0.1 \%$ probability level, respectively.

$0.84 \mathrm{~g} \cdot \mathrm{m}^{-2}$ at 4 plants $/ \mathrm{m}^{2}$ to $4.27 \mathrm{~g} \cdot \mathrm{m}^{-2}$ at 50 plants $/ \mathrm{m}^{2}$ then decreased slightly to $3.50 \mathrm{~g} \cdot \mathrm{m}^{-2}$ at 100 plants $/ \mathrm{m}^{2}$. Oil yield from the tertiaries decreased with increasing stand density. The total oil yield was not significantly different between stand densities of $4,12,25$, or 50 plants $/ \mathrm{m}^{2}$ but at the highest stand density of 100 plants $/ \mathrm{m}^{2}$, it decreased.

Oil composition. The percentage of transanethole in the oil (Table 4 ) from the primary umbels is significantly $(p<0.05)$ higher for 4 plants $/ \mathrm{m}^{2}(75 \%$ of the volatile components of the oil) than the percentage trans-anethole of primary umbel oil for any other density measured. In the second-order umbels, transanethole concentration for 4 plants $/ \mathrm{m}^{2}$ is $72 \%$ and it is significantly higher $(p<0.05)$ for than for 12,25 , or 50 plants $/ \mathrm{m}^{2}$ but not different from 100 plants $/ \mathrm{m}^{2}$. Among the tertiaries, the trend is for increasing density to increase the percentage trans-anethole in the oil.

\section{Discussion}

Canopy architecture. The architecture of the canopy is determined by numerous factors including, but not limited to, the number of stems, the total number of umbels and the distribution of the total number of umbels between the various umbel orders. Altering stand density substantially altered the canopy architecture.

Stand density is dependent on the many factors controlling plant growth, death and reproduction, but here it is primarily dependent upon the applied treatment density. The treat- ment density to which each plot was thinned ensured stands of the required densities, with square spacing arrangements, in all but the 100 plant $/ \mathrm{m}^{2}$ plots. In these plots self-thinning reduced the stand density to an average of 77 plants $/ \mathrm{m}^{2}$, as shown by the number of primary umbels.

Each plant produces a maximum of one primary umbel, so the number of primary umbels per unit area is dependent upon the stand density. In all but the 100 plants $/ \mathrm{m}^{2}$ plots, the number of primary umbels was equal to the number of plants for the applied treatment density, except in the few occasions where a stem suffered mechanical damage. At 100 plants $/ \mathrm{m}^{2}$, self-thinning reduced the number of primary umbels. The number of secondary and tertiary umbels also varied with stand density in such a way that the total number of umbels produced was not altered by stand density. At low planting densities, fennel plants like carrot plants (Gray and Steckel, 1983; Noland et al., 1988) produced more lateral branches and consequently more higher order umbels.

A further influence of stand density on canopy architecture is the effect on canopy depth. This is bestillustrated in Fig. 2. The depth of the generative canopy is greatly increased at a low planting density. This has a marked influence on the efficiency of mechanical harvesting. Although the total number of umbels is constant across all tested stand densities, the depth of canopy and the subsequent amount of stem material to be handled will be greatly increased at the lower stand densities. Based on canopy architecture, a stand density of 50 plants $/ \mathrm{m}^{2}$ is predicted to produce the ideal canopy for mechanical harvesting in the commercial situation.

Pollen availability. The availability of pollen for the pollination of receptive stigmas is dependent upon many factors including pollen production, dispersal and viability. A key factor disclosed by the results of this trial is the timing of pollen production in relation to the timing of stigma receptivity. Individual fennel flowers are strongly protandrous and a potential problem in the timing of pollen delivery exists. It is not possible to deduce from this experiment, the ratio of umbels producing pollen to umbels with receptive stigmas necessary for adequate pollination. However, the results obtained support the hypothesis that there is insufficient pollen available to fully fertilise the umbels that are receptive late in the season. At higher crop densities, there are fewer flowers of higher umbel orders produced, resulting in less pollen being available to pollinate the flowers of the preceding order.

At a plant density of 4 plants $/ \mathrm{m}^{2}$, the relatively high number of tertiary umbels ensures pollen is produced over a long period. There is a balance between the number of umbels producing pollen and the number of umbels with receptive stigmas. In March, at this density, there is a ratio of one pollen producing umbel for every two pollen receiving umbels. This balance also exists at a plant density of 12 plants $/ \mathrm{m}^{2}$ although the flowering season is slightly shorter than that at 4 plants $/ \mathrm{m}^{2}$. Pollen appears to be available for the pollination of most umbels. At 25 plants $/ \mathrm{m}^{2}$ the balance between pollen production and stigma receptivity exists in the early to midseason. Towards the end of the season, there is a peak in receptivity of the tertiary umbels and there are many more tertiaries receptive than there are flowers producing pollen. There may or may not be sufficient pollen available for pollination of the tertiary umbels at this density. This effect becomes more pronounced with increasing stand density. At 50 and 100 plants $/ \mathrm{m}^{2}$, the trend suggests that there may be insufficient pollen available for the pollination of the tertiaries and perhaps insufficient pollen available for the pollination of the secondaries. For a density of 100 plants $/ \mathrm{m}^{2}$, in early March there is a ratio of only one pollen-producing umbel for every 20 pollen receiving umbels and by late March, there are still pollen receiving umbels but virtually no pollen producing umbels. Further studies using pollen trapping would be required to prove the hypothesis, as it is not possible to do so from these data.

The increase in length of flowering time for individual umbel orders, is comparable with that in carrots, where the primary umbels show a greater breadth of flowering time at higher planting densities (Gray and Steckel, 1983, 1985). The increase in flowering time helps to overcome some of the effects of protandry, since the duration of pollen production by primary umbels is increased. However, this would not be sufficient to ensure adequate pollen availability for pollination of the secondaries and tertiaries to follow. Since $53 \%$ of the umbels produced at a stand density of 100 
plants $/ \mathrm{m}^{2}$ are secondary umbels, inadequate pollination of this umbel order has the potential to greatly reduce oil yield.

Fruit set. Extrapolation of the results on fruit set, from the trial to a crop situation, must be undertaken with caution. An unavoidable weakness of this trial is the close proximity of the different density plots. Close proximity is necessary in order to minimise environmental variation between the plots, however it is possible that the inner umbellules of the higher density plots were pollinated by the umbels of the adjacent lower density plots. Plots were separated by a minimum of $1 \mathrm{~m}$ to reduce cross pollination between plots, however, since the crop is both insect and wind pollinated, cross pollination cannot be ruled out. Therefore, data on fruit set and oil yield may not be as meaningful as data on pollen availability and plant architecture.

In addition, pollen availability is only broadly related to the number of open anthers. It is also influenced by other factors such as pollen dispersion, which is in turn influenced by such factors as weather and bee activity. This could be tested by hand pollination, but hand pollination was outside the scope of this investigation. Fruit set itself is also only broadly related to pollination with other factors such as competition for assimilate influencing set or retention to final harvest.

Oilyield and quality. Oilyield and trans-anethole content are the most important variables from a commercial point of view.

Differences in fruit set can explain most of the differences in oil yield associated with stand density.

Changes in trans-anethole content are perhaps influenced by the relative maturity of the umbels, rather than density per se, and are therefore related to the length of the respective flowering period. As umbels mature the transanethole content of the fruit rises, peaking as the fruit begin to dry at maturity (Peterson, 1990). The more mature umbels present at the time of harvest the higher will be the transanethole content of the oil and the better the oil quality. This means that the fewer umbel orders present, the higher the quality of the oil since there will be less gradation in maturity. As umbels mature and the fruit dry, two problems occur: a) the seed begins to fall and yield is reduced; and b) the seed loses moisture and becomes harder and less permeable, thus the oil is extracted less efficiently by the distillation process. Therefore, a crop with uniform maturity and hence a definitive harvest schedule, is the easiest to harvest at the most appropriate time to obtain the highest yield of the highest quality oil. A stand density of 50 plants $/ \mathrm{m}^{2}$ is therefore recommended.

Recommendation for management. The canopies obtained at densities of 25 to 50 plants $/ \mathrm{m}^{2}$ are the easiest to harvest because of the reduced volume of stem material that must be harvested in order to obtain the same volume of umbels. However, crop management to capture the advantage of these results requires modification of the existing commercial stand density.

Management practices such as harrowing or thinning of the crop could be used to maintain 50 plants $/ \mathrm{m}^{2}$ for the main portion of the crop, although in many instances self-thinning will tend to maintain this density naturally. Areas of lower stand density (about 4 plants $/ \mathrm{m}^{2}$ ) will give an extended period of pollen production to provide adequate pollen for pollination of the secondary and tertiary umbels at this stand density. It is expected that rows at low density, interspersed throughout the crop would achieve this objective.

Another possibility is to take advantage of the edge effects which exist because the plants on the boundary of the crop are effectively at a lower plant density than those within the stand (Benjamin and Sutherland, 1992). To capture this benefit, fennel could be planted with wider spacings between the beds. An alternative may be to sow some beds at a lower density than others. It is postulated that these modifications will provide a uniform crop at harvest time by reducing the proportion of higher order umbels while enhancing pollen production to allow for adequate pollination and seed set.

\section{Conclusion}

Areas of low plant density are required to produce adequate pollen for pollination of all umbels in fennel stands. Higher stand densities result in more uniform crops. Therefore, it is recommended that commercial crops contain areas of both high and low stand density.

The results of this study go toward explaining the apparent anomaly between yield of small experimental plots and commercial fields. Small, experimental crops have a large perimeter to internal area ratio. Edge plants are effectively at a lower plant density and this means that there are a large number plants at low stand density to provide pollen for the inner plants at a higher stand density.

The trial also demonstrates the complications of yield interpretation from density trials where effects such as pollination can have a dominant influence.

\section{Literature Cited}

Baswana, K.S. 1984. Role of insect-pollinators on seed production in coriander and fennel. S. Ind. Hort. 32:117-118.

Bell, C.R. 1971. Breeding systems and floral biology of the Umbelliferae or evidence for specialization in unspecialized flowers, p. 93-107. In: V.H. Heywood (ed.). The biology and chemistry of the
Umbelliferae. Academic Press, London.

Benjamin, L.R.and R.A. Sutherland. 1992. Control of mean root weight in carrots (Daucus carota) by varying within- and between-row spacing. J Agr. Sci. Cambridge 119:59-70.

Choudhry, A.R. 1959. Some breeding studies in fennel and coriander. Agr. Pakistan 10:477-486.

Desmarest, P. 1978. New aspects of fennel cultivation in France. Acta Hort. 73:289-295.

Gray, D.and J.R.A. Steckel. 1983. Seed quality in carrots: The effects of seed crop plant density, harvest date and seed grading on seed and seedling variability. J. Hort. Sci. 58:393-401.

Gray, D.and J.R.A. Steckel. 1985. Variation in flowering time as a factor influencing variability in seedling size in the subsequent carrot (Daucus carota L.) crop. J. Hort. Sci. 60:77-81.

Gray, D., J.R.A. Steckel, and J.A. Ward. 1983. Studies on carrot seed production: Effects of plant density on yield and components of yield. J. Hort. Sci. 58:83-90.

Guenther, E. 1972. The essential oils. Robert E. Krieger Publ. Co., Huntington, N.Y.

Hart, M.A. 1987. Department of Primary Industries notes: Fennel. Austral. Govt. Printing Serv., Hobart, Tasmania.

Hawthorn, L.R., G.E. Bohart, E.H. Toole, W.P. Nye, and M.D. Levin. 1960. Carrot seed production as affected by insect pollination. Utah Agricultural Experiment Station Bulletin. 422:1-18.

Hunault, G., P. Desmarest, and J. Du Manoir. 1989. XI Foeniculum vulgare Miller: Cell culture, regeneration, and the production of anethole, $p$. 185-209. In: Y.P.S. Bajaj (ed.). Medicinal and aromatic plants. Springer-Verlag, Berlin.

Jansen, P.C.M. 1981. Spices, condiments and medicinal plants in Ethiopia, their taxonomy and agricultural significance. Centre Agr. Publ. Documentation, Wageningen.

Noland, T.L., J.D. Maguire, R.N. Oliva, K.J. Bradford, J.L. Nelson, D. Grabe, and S. Currans. 1988. Effect of plant density on carrot seed yield and quality under seed-to-seed production systems in California, Oregon, and Washington. J. Appl. Seed Prod. 6:36-43.

Paupardin, C., C. Leddet, and R. Gautheret. 1990. Histo-chemical investigations on fennel. Physiological connection between terpen's nature and histological structure of secretory apparatus. I. J. Jpn. Bot. 65:33-44.

Peterson, L.E. 1990. A study of some factors affecting the yield and composition of fennel oil (Foeniculum vulgare Mill.). PhD diss. Univ. Tasmania.

Pillai, P.K.T.and M.C. Nambiar. 1982. Condiments. In: C.K. Atal and B.M. Kapur (eds.). Cultivation and utilization of aromatic plants. Reg. Res. Lab., New Delhi.

Ramanujam, S., B.S. Joshi, and M.B.L. Saxena. 1964. Extent of randomness of cross-pollination in some umbelliferous species of India. Ind. J. Genet. Cited by Jansen, P.C.M. 1981. Centre Agr. Publ. Documentation, Wageningen.

SAS Institute. 1996. Statistical package, version 6.12, 1989-1996, SAS Inst. Inc., Cary, N.C.

Sundararaj, D.D., G. Soundrapandian, and A.M.M. Alikhan. 1963. Preliminary observations on fennel (Foeniculum vulgare Gaertn.) with special reference to floral biology. Madras Agr. J. 50:235-238. 